\title{
Diosmetin and tamarixetin (methylated flavonoids): A review on their chemistry, sources, pharmacology, and anticancer properties
}

\author{
Eric Wei Chiang Chan ${ }^{1 *}$, Ying Ki Ng${ }^{1}$, Chia Yee Tan ${ }^{1}$, Larsen Alessandro ${ }^{1}$, Siu Kuin Wong ${ }^{2}$, Hung Tuck Chan ${ }^{3}$ \\ ${ }^{1}$ Faculty of Applied Sciences, UCSI University, Kuala Lumpur, Malaysia. \\ ${ }^{2}$ School of Foundation Studies, Xiamen University Malaysia, Sunsuria, Malaysia. \\ ${ }^{3}$ Faculty of Agriculture, University of the Ryukyus, Okinawa, Japan.
}

\begin{tabular}{l}
\hline ARTICLE INFO \\
\hline Received on: $21 / 10 / 2020$ \\
Accepted on: $26 / 12 / 2020$ \\
Available online: 05/03/2021 \\
\\
\hline Key words: \\
Methylated flavonoids, \\
diosmetin, tamarixetin, \\
cytotoxic, anti-cancer effects.
\end{tabular}

\begin{abstract}
This review begins with an introduction to the basic skeleton and classes of flavonoids. Studies on flavonoids have shown that the presence or absence of their functional moieties is associated with enhanced cytotoxicity toward cancer cells. Functional moieties include the $\mathrm{C} 2-\mathrm{C} 3$ double bond, $\mathrm{C} 3$ hydroxyl group, and 4-carbonyl group at ring $\mathrm{C}$ and the pattern of hydroxylation at ring B. Subsequently, the current knowledge on the chemistry, sources, pharmacology, and anticancer properties of diosmetin (DMT) and tamarixetin (TMT), two lesser-known methylated flavonoids with similar molecular structures, is updated. DMT is a methylated flavone with three hydroxyl groups, while TMT is a methylated flavonol with four hydroxyl groups. Both DMT and TMT display strong cytotoxic effects on cancer cell lines. Studies on the anticancer effects and molecular mechanisms of DMT included leukemia and breast, liver, prostate, lung, melanoma, colon, and renal cancer cells, while those of TMT have only been reported in leukemia and liver cancer cells. These findings suggest that flavones lacking the $\mathrm{C} 3$ hydroxyl group at ring $\mathrm{C}$ are more cytotoxic than flavonols having the $\mathrm{C} 3$ hydroxyl group. The in vitro and in vivo cytotoxic activities of DMT and TMT against cancer cells involve different molecular targets and signaling pathways. From this study, it is clear that little is known about the pharmacology and anticancer properties of DMT and TMT. The potentials for further research into these aspects of the two lesser-known methylated flavonoids are enormous.
\end{abstract}

\section{INTRODUCTION}

Flavonoids represent the largest family of phenolic secondary metabolites from plants with more than 9,000 compounds reported (Wang et al., 2011). They occur in most herbs, fruits, and vegetables (Kopustinskiene et al., 2020; Panche et al., 2016). These polyphenols have a molecular structure consisting of two benzene rings $\mathrm{A}$ and $\mathrm{B}$ that are joined by a heterocyclic pyran ring $\mathrm{C}$ forming the benzopyrone (C6-C3-C6) moiety (Raffa et al., 2017; Singh et al., 2014). Rings A and C are composed of the chroman (C6-C3) nucleus (Kanadaswami et al., 2005). The basic skeleton along with the functional moieties is shown in Figure 1.

\footnotetext{
${ }^{*}$ Corresponding Author

Eric Wei Chiang Chan, Faculty of Applied Sciences,

UCSI University, Cheras, Malaysia.

E-mail: chanwc@ucsiuniversity.edu.my; erchan@yahoo.com
}

Flavonoids are subdivided into classes including aurones, chalcones, flavonols, flavones, flavanones, flavan-3-ols, anthocyanins, and isoflavones (Kar Mahapatra et al., 2015, 2019). The majority of the flavonoids have the B ring linked in position 2 to the $\mathrm{C}$ ring (Fig. 1), and they include aurones, chalcones, flavones, flavonols, flavanones, and flavanols (e.g., Guven et al., 2019; Panche et al., 2016; Raffa et al., 2017; Singh et al., 2014). Aurones are a subclass of flavones (Boumendjel, 2003), while chalcones are precursors of flavonoids and isoflavones (Kar Mahapatra et al., 2015). Flavones (e.g., apigenin and luteolin) have a C2-C3 double bond and a 4-carbonyl group but they lack the C3 hydroxyl group at ring C. Flavonols (e.g., fisetin, quercetin, morin, and myricetin) possess all the three functional moieties (Fig. 1). Flavanones (e.g., naringenin, hesperitin, and taxifolin) lack the $\mathrm{C} 2-\mathrm{C} 3$ double bond, while flavanols (e.g., catechin and epicatechin) lack the $\mathrm{C} 2-\mathrm{C} 3$ double bond and the 4-carbonyl group (Guven et al., 2019; Panche et al., 2016). Flavonoids in which the B ring is linked at positions 3 and 4 to the $\mathrm{C}$ ring are called isoflavones (e.g., genistein and 


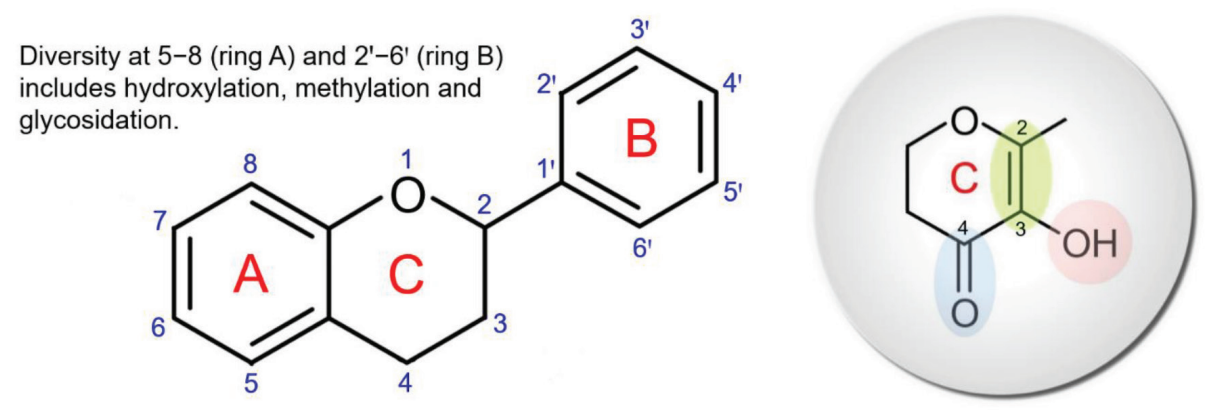

Figure 1. Basic skeleton of flavonoids (left) showing the $\mathrm{C} 2-\mathrm{C} 3$ double bond, 4-carbonyl group, and $\mathrm{C} 3$ hydroxyl group of flavonols at ring $\mathrm{C}$ (right).

daidzein) and neoflavonoids (e.g., calophyllolide), respectively (Panche et al., 2016). In nature, flavonoids occur as aglycones, glycosides, and methylated derivatives.

Flavonoids are endowed with health-promoting properties including nutraceutical, pharmaceutical, and cosmeceutical applications (Panche et al., 2016). Pharmacological properties include antioxidant, antimicrobial, antiallergic, antiinflammatory, anticarcinogenic, and antidiabetic effects (Guven et al., 2019; Raffa et al., 2017). The medical applications of flavonoids involve protection against cancer and other diseases, such as cardiovascular, rheumatic, obesity, high cholesterol, hypertension, and neurological disorders (Ballard and Junior, 2019; Havsteen, 2002).The anticancer effects of flavonoids operate during the stages of initiation, promotion, and progression of carcinogenesis. In the initiation and promotion stages, flavonoids can inhibit cell proliferation (Abotaleb et al., 2019; Ballard and Junior, 2019). At the stage of progression, flavonoids can inhibit proangiogenesis, regulate metastasis, induce cytotoxicity and apoptosis, promote cell cycle arrest, and reverse multidrug resistance (MDR) or a combination of these mechanisms (Abotaleb et al., 2019; Chahar et al., 2011; Raffa et al., 2017). The antitumor activities of flavonoids include the induction of apoptosis, suppression of protein tyrosine kinase activity, antiproliferation, antimetastasis, anti-invasive effects, and antiangiogenesis (Kanadaswami et al., 2005). Many studies have provided scientific evidence for the anticancer properties of flavonoids in vitro and in vivo (Ren et al., 2013; Wang, 2000). Flavonoids such as quercetin and flavopiridol are now in phase II human clinical trials for different cancers.

When tested against different cancer cells, cytotoxicity of various classes of flavonoids based on $\mathrm{IC}_{50}$ values was ranked as flavones $>$ flavonols $>$ flavanones $>$ isoflavones $\sim$ flavanols (Kuntz et al., 1999; Li et al., 2008; Plochmann et al., 2007; Sak, 2014). Flavones have the strongest cytotoxicity over the other groups of flavonoids due to the presence of the $\mathrm{C} 2-\mathrm{C} 3$ double bond, compared to the 4-carbonyl (4-oxo or 4-keto) group and the C3-hydroxyl group at ring C (Fig. 1). Disparity exists as stronger cytotoxicity has been reported in flavonols than flavones, for example, quercetin $>$ kaempferol $>$ apigenin (Wang et al., 2018).

The pattern of hydroxylation in ring $\mathrm{B}$ influences the degree of cytotoxicity; for example, the ortho-hydroxylated quercetin $\left(3^{\prime}\right.$ and $\left.4^{\prime}\right)$ is three times more cytotoxic than the meta-hydroxylated morin $\left(2^{\prime}\right.$ and $\left.4^{\prime}\right)$. Other factors influencing cytotoxicity are $O$-methylation and glucuronidation in the A ring which are associated with enhanced cytotoxicity, while a

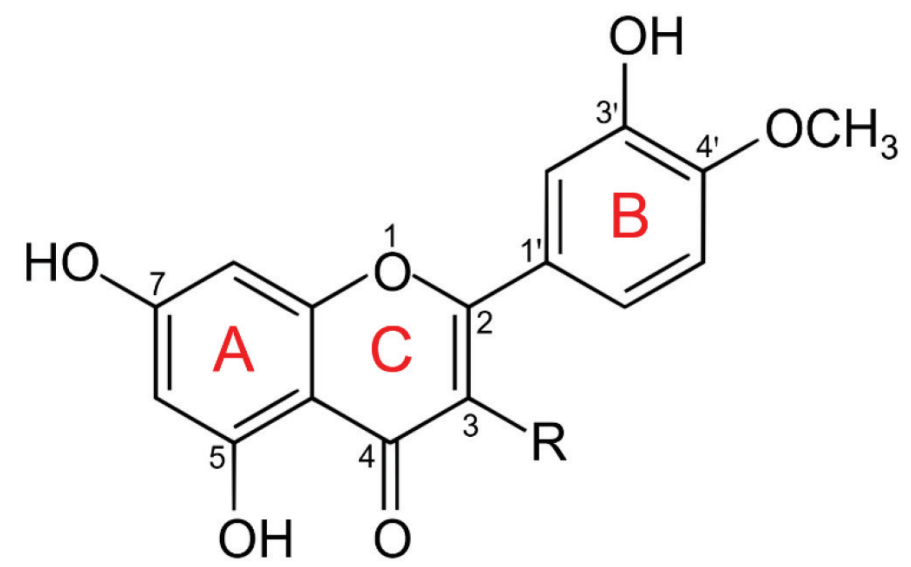

Figure 2. Molecular structures of diosmetin $(\mathrm{R}=\mathrm{H})$ (left) and TMT $(\mathrm{R}=\mathrm{OH})$ (right).

higher number of hydroxyl residues and solubility are inversely correlated with cytotoxicity (Plochmann et al., 2007).

When tested against five different cancer cell lines, flavonoids can be categorized into those with strong and those with weak in vitro cytotoxic effects (Chang et al., 2008). Apigenin, luteolin, and fisetin of the strong category are characterized by having two hydroxyl groups in rings $\mathrm{AC}$, while myricetin and morin of the weak category have three hydroxyl groups in rings $\mathrm{AC}$ (Fig. 1). Both naringenin and apigenin share the same molecular structure. Naringenin without the 2,3-double bond displayed weak cytotoxic effects suggesting the importance of the double bond between C2 and C3 (Chang et al., 2008). Genistein and daidzein are isoflavones in which ring $\mathrm{B}$ is attached to ring $\mathrm{C}$ at $\mathrm{C} 3$ instead of $\mathrm{C} 2$.

For polymethylated flavonoids (e.g., natsudaidain), a methoxy group at $\mathrm{C} 8$ and a hydroxyl group at $\mathrm{C} 3$ are essential for their antiproliferative activity of the flavonoids (Kawaii et al., 1999). Isoflavones (e.g., genistein and daidzein) are flavonoids in which the $\mathrm{B}$ ring is linked in position 3 of the $\mathrm{C}$ ring (Chang et al., 2008; Lopez-Lazaro, 2002; Lopez-Lazaro et al., 2002). Generally, isoflavones have weaker cytotoxicity than the other flavonoids linked in position 2. In addition, the sugar moiety of flavonoids (e.g., rutin and isoquercetin) reduces their cytotoxic activity (Lopez-Lazaro, 2002; Lopez-Lazaro et al., 2002). In flavonoids, the ring $\mathrm{B}$ catechol moiety of flavonoids (e.g., $3^{\prime}, 4^{\prime}$-diOH) and the - OMe group at $5^{\prime}$ are beneficial toward their cytotoxicity, while glycosylation at $\mathrm{C} 5$ of ring A has adverse effects on cytotoxicity 
(Wang et al., 2018). This review begins with an introduction to the basic skeleton and different classes of flavonoids. Subsequently, the current knowledge on the chemistry, sources, pharmacology, and anticancer properties of diosmetin (DMT) and tamarixetin (TMT), two lesser-known methylated flavonoids with similar molecular structure, is updated. Sources of information cited were from Google Scholar, PubMed, PubMed Central, Science Direct, J-Stage, PubChem, and Directory of Open Access Journals.

\section{CHEMISTRY AND SOURCES}

\section{Diosmetin}

DMT (4'-methylluteolin, luteolin 4'-methyl ether or $5,7,3^{\prime}$-trihydroxy-4'-methoxyflavone) is a natural methylated flavone. Its molecular formula is $\mathrm{C}_{16} \mathrm{H}_{12} \mathrm{O}_{6}$ and its molecular weight is $300 \mathrm{~g} / \mathrm{mol}$ (Patel et al., 2013). DMT has three hydroxyl groups at 5, 7, and 3' positions (Fig. 2). Being a flavone, the molecule has a $\mathrm{C} 2-\mathrm{C} 3$ double bond and a 4-carbonyl group but lacks the C3 hydroxyl group at ring C. The DMT molecule is structurally similar to that of luteolin with the exception of the $4^{\prime}$-methoxy group in DMT and the $4^{\prime}$-hydroxyl group in luteolin. DMT is an aglycone of diosmin or DMT 7-O-rutinoside (Chen et al., 2019a).

DMT has been isolated from many plant species. They include the aerial parts of Soroseris hookeriana (Hooker's Soroseris) (Meng et al., 2000) and Petroselinum crispum (parsley) (Yoshikawa et al., 2000), Citrus fruit juices (AbadGarcia et al., 2014), and flowers of Chrysanthemum morifolium (chrysanthemum) (Lin and Harnly, 2010; Xie et al., 2009). From the flowers and leaves of Origanum vulgare (oregano), the contents of DMT have been reported to be 0.18 and $0.04 \mathrm{DW}: \mathrm{mg} / \mathrm{g}$ dry weight (Radušienè et al., 2008). From the ethyl acetate fraction of the methanol extract of Eleocharis dulcis (water chestnut) peel, the content of DMT $(30 \mathrm{mg} / \mathrm{g})$ ranked second to that of fisetin (32 mg/g) (Zhan et al., 2016). Glycosides of DMT are commonly found in Citrus fruit juices, notably those of Citrus medica and Citrus bergamia (Caristi et al., 2006; Hostetler et al., 2017).

\section{Tamarixetin}

TMT (4'-O-methylquercetin, quercetin 4'-methyl ether or $3,5,7,3^{\prime}$-tetrahydroxy-4'-methoxy flavonol) is a natural methylated flavonol with a molecular formula of $\mathrm{C}_{16} \mathrm{H}_{12} \mathrm{O}_{7}$ and molecular weight of $316 \mathrm{~g} / \mathrm{mol}$. TMT has four hydroxyl groups at 3, 5, 7, and 3 ' positions (Fig. 2). Being a flavonol, the molecule has a $\mathrm{C} 2-\mathrm{C} 3$ double bond, a 4-carbonyl group, and a $\mathrm{C} 3$ hydroxyl group at ring C. It is structurally similar to isorhamnetin (3'-O-methylquercetin) and quercetin. TMT has been isolated from the leaves of Tamarix ramosissima (salt cedar) (Sultanova et al., 2001), Azadirachta indica (neem) (Yadav et al., 2017), and Psidium guajava (guava) (Shao et al., 2014).

\section{PHARMACOLOGY}

\section{Diosmetin}

The anti-inflammatory, antioxidant, and hepatoprotective effects of DMT have been reported (Yang et al., 2017). Other pharmacological properties of DMT include antimicrobial (Meng

Table 1. Anticancer effects and molecular mechanisms of diosmetin (DMT).

\begin{tabular}{|c|c|}
\hline Cancer cell line and type & Anticancer effect and molecular mechanism of diosmetin (reference) \\
\hline MDA-MB-468 breast & $\begin{array}{l}\text { Inhibits cell proliferation, causes G1 cell cycle arrest, and exerts cytostatic effects via CYP1 enzyme-mediated conversion to luteolin (Androutsopoulos } \\
\text { et al., 2009a) }\end{array}$ \\
\hline MCF-7 breast & Inhibits cell proliferation and its cytotoxic effects are dependent on CYP1 enzyme conversion to luteolin (Androutsopoulos et al., 2009b) \\
\hline MDA-MB-231 breast & Exerts antiproliferative and proapoptotic activities via cell cycle arrest and the mitochondria-mediated intrinsic apoptotic pathway (Wang et al., 2019) \\
\hline HepG2 liver & $\begin{array}{l}\text { Exerts synergistic cytostatic effects and arrest G2/M cell cycle when applied with luteolin via CYP1A-catalyzed metabolism, activation of c-jun } \\
\text { N-terminal kinase (JNK) and extracellular signal-regulated kinase (ERK), and P53/P21 upregulation (Androutsopoulos and Spandidos, 2013) }\end{array}$ \\
\hline HepG2 liver & Induces cell apoptosis by upregulating p53 via the transforming growth factor $\beta$ (TGF- $\beta$ ) signal pathway (Liu et al., 2016a) \\
\hline SK-HEP-1 liver & $\begin{array}{l}\text { Inhibits cell metastasis by downregulating the expression levels of MMP-2 and MMP-9 via the protein kinase (PKC)/ mitogen-activated protein kinase } \\
\text { (MAPK)/metalloproteinase (MMP) pathways (Liu et al., 2016b) }\end{array}$ \\
\hline HepG2 liver & Inhibits cell proliferation and induces apoptosis by regulating autophagy via the mammalian target of rapamycin (mTOR) pathway (Liu et al., 2016c) \\
\hline HepG2 liver & $\begin{array}{l}\text { Triggers apoptosis by activation and inactivation of the } \mathrm{p} 53 / \mathrm{Bcl}-2 \text { pathway and the Notch3/nuclear factor-kappa B (NF- } \mathrm{B} \text { ) pathway, respectively (Qiao } \\
\text { et al., 2016) }\end{array}$ \\
\hline HepG2 liver & Inhibits cell proliferation and promotes cell apoptosis and cell cycle arrest by targeting chk2 (Ma and Zhang, 2020) \\
\hline PC-3 and LNCaP prostate & Suppresses cell proliferation via induction of apoptosis and cell cycle arrest (Oak et al., 2018) \\
\hline NSCLC lung & $\begin{array}{l}\text { Induces apoptosis by producing reactive oxygen species (ROS) and reducing Nrf2 stability via suppression of the PI3K/Akt/glycogen synthase kinase } 3 \\
\text { beta (GSK-3 } \beta \text { ) pathway (Chen et al., 2019b) }\end{array}$ \\
\hline B16F10 melanoma & Suppresses tumor progression and metastasis by inducing cell death and inhibiting angiogenesis (Choi et al., 2019) \\
\hline HCT-116 colon & Induces apoptosis, inhibits cell proliferation, and arrest G2/M cell cycle mediated by the membrane death receptor (Koosha et al., 2019a) \\
\hline HCT-116 colon xenograft & Reduces tumor growth in nude mice by downregulation of Bcl-2 and overexpression of Bax (Koosha et al., 2019b) \\
\hline ACHN renal & Induces apoptosis and cytotoxicity by reducing protein kinase B (AKT) phosphorylation via p53 upregulation (Qiu et al., 2020) \\
\hline K562 leukemia & Induces apoptosis via activation of caspases 8 and $3 / 7$ and the death-inducing cytokine tumor necrosis factor alpha (TNF $\alpha)(\mathrm{Roma}$ et al., 2019) \\
\hline
\end{tabular}

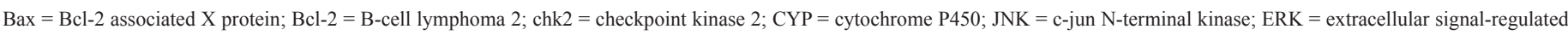

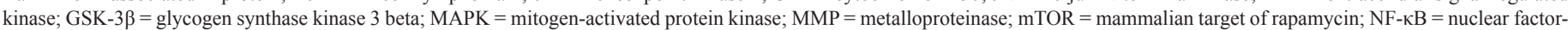

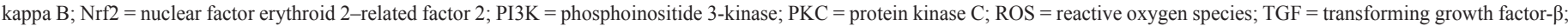
and $\mathrm{TNF} \alpha=$ tumor necrosis factor alpha. 
et al., 2000), oestrogenic (Yoshikawa et al., 2000), neuroprotective (Bhatt and Benzeroual, 2013), drug-drug interaction (Bajraktari and Weiss, 2020), osteoblastic (Hsu and Kuo, 2008), and MDR protein inhibitory (van Zanden et al., 2005) activities.

\section{Tamarixetin}

TMT displays anti-inflammatory (Lesjak et al., 2018; Park et al., 2018), cardioprotective (Fan et al., 2019; Hayamizu et al., 2018), gastroprotective (Yadav et al., 2017), and MDR protein inhibitory (van Zanden et al., 2005) activities.

\section{ANTICANCER PROPERTIES}

\section{Diosmetin}

Against Caco-2 and HT-29 and colon cancer cells, the $\mathrm{EC}_{50}$ values of DMT were 108 and $204 \mu \mathrm{M}$, respectively (Kuntz et al., 1999). The cytotoxicity of DMT was 1.2 and 1.8 times weaker than those of luteolin. Against COLO 205 colon cancer cells, the $\mathrm{IC}_{50}$ value of DMT $(82.9 \mu \mathrm{M})$ was slightly stronger than luteolin $(96.9 \mu \mathrm{M})$ while diosmin $(>200 \mu \mathrm{M})$ did not show any activity (Xie et al., 2009). Against A549 lung cancer cells, the $\mathrm{IC}_{50}$ value of DMT $(101 \mu \mathrm{g} / \mathrm{mL})$ was weaker than luteolin $(59.6 \mu \mathrm{g} / \mathrm{ml})$ and fisetin $(86.5 \mu \mathrm{g} / \mathrm{ml})$ (Zhan et al., 2016). Besides the structural features of flavonoids, for example, flavones versus flavonols, these results show that cytotoxicity also depends on the type of cancer cells tested. Cytotoxic effects of DMT toward HCT-116 colon cancer cells $(3.6 \mu \mathrm{g} / \mathrm{ml})$ were 14 times more potent than toward CCD-841 normal colon cells $(52 \mu \mathrm{g} / \mathrm{ml})$ (Koosha et al., 2019a).

The anticancer effects and molecular mechanisms of DMT toward different cancer cell lines are listed in Table 1. Against MCF-7 and MDA-MB-468 breast cancer cells, DMT inhibits cell proliferation, arrests G1 cell cycle, and exerts enhanced cytotoxic or cytostatic effects via CYP1 enzyme-mediated conversion to luteolin (Androutsopolous et al., 2009a, 2009b). DMT displays antiproliferative and proapoptotic activities against MDA-MB-231 breast cancer cells via cell cycle arrest and the mitochondriamediated intrinsic apoptotic pathway (Wang et al., 2019).

When used in combination against HepG2 liver cancer cells, DMT and luteolin exhibit cytostatic effects and arrest G2/M cell cycle via CYP1A-catalyzed metabolism, P53/P21 upregulation, and JNK and ERK activation (Androutsopolous and Spandidos, 2013). When tested with HepG2 and SK-HEP-1 liver cancer cells, DMT induces cell apoptosis by upregulating p53 via the TGF- $\beta$ signal pathway (Liu et al., 2016a); inhibits cell metastasis by downregulating the expression levels of MMP-2 and MMP-9 via the PKC/MAPK/MMP pathways (Liu et al., 2016b); inhibits cell proliferation by inducing apoptosis and by regulating autophagy via the mTOR pathway (Liu et al., 2016c); triggers apoptosis by activation of the $\mathrm{p} 53 / \mathrm{Bcl}-2$ pathway and inactivation of the Notch3/NF- $\kappa$ B pathway (Qiao et al., 2016); suppresses cell proliferation; and enhances cell apoptosis and cell cycle arrest by targeting chk2 (Ma and Zhang, 2020).

The anticancer properties of DMT were studied using other cancer cells such as PC-3 and LNCaP prostate [1], NSCLC lung [2], B16F10 melanoma [3], HCT-116 colon [4], ACHN renal [5], and K562 leukemia [6] cell lines (Table 1). DMT suppresses cell proliferation of [1] via induction of apoptosis and cell cycle arrest (Oak et al., 2018); induces apoptosis of [2] by producing
ROS and reducing Nrf2 stability via suppression of the PI3K/ Akt/GSK-3 $\beta$ pathway (Chen et al., 2019b); and suppresses tumor progression and metastasis of [3] by inducing cell death and inhibiting angiogenesis (Choi et al., 2019). DMT promotes apoptosis, inhibits cell proliferation, and arrests G2/M cell cycle of [4] mediated by the membrane death receptor (Koosha et al., 2019a); reduces tumor growth of [4] in nude mice via downregulation of Bcl-2 and overexpression of Bax (Koosha et al., 2019b); promotes apoptosis and cytotoxicity of [5] by reducing AKT phosphorylation via p53 upregulation (Qiu et al., 2020); and induces apoptosis of [6] via activation of caspases 8 and 3/7 and the death-inducing cytokine TNF $\alpha$ (Roma et al., 2018).

\section{Tamarixetin}

Against A549 and HCC44 lung cancer cells, cytotoxicity of TMT was 19.6 and $20.3 \mu \mathrm{M}$, respectively (Sak et al., 2018). Its cytotoxicity was 3.7 and 5.3 times stronger than that of quercetin. The $\mathrm{IC}_{50}$ values of TMT were comparable to those of isorhamnetin (3'-O-methyl quercetin) with values of 26.6 and $15.9 \mu \mathrm{M}$, respectively. Cytotoxicity of TMT against four different leukemia cell lines, Based on IC50 values, cytotoxicity of TMT against four different leukemia cell lines were $5.5 \mu \mathrm{M}$ for U937 cells, $7.5 \mu \mathrm{M}$ for HL-60 cells, $7.5 \mu \mathrm{M}$ for Molt-3 cells and 24 $\mu \mathrm{M}$ for K562 cells (Nicolini et al., 2014). For Molt-3 and HL60 leukemia cells, $\mathrm{IC}_{50}$ values were both $7.5 \mu \mathrm{M}$. In a study on the antiproliferative effects of quercetin and catechin metabolites in $\mathrm{IC}_{50}$ values, the cytotoxicity of TMT $(82 \mu \mathrm{M})$ was comparable to quercetin $(85 \mu \mathrm{M})$ when tested against Caco-2 colon cancer cells (Delgado et al., 2014). Against MCF-7 breast and BxPC3 pancreatic cancer cells, cytotoxicity of TMT was 1.5 and 3.0 times weaker than quercetin, respectively. When tested against AGS gastric, B16F10 melanoma, C6 glioma, and HeLa cervical cancer cells using quercetin, 7-O-methylated quercetin, and 3-O-methylated quercetin, TMT exhibited the strongest cytotoxic activity (Darsandhari et al., 2020).

There are only two studies on the anticancer effects and molecular mechanisms of TMT (Table 2). Against doxorubicin-resistant K562/ADR leukemia cells, TMT inhibits cell proliferation, arrests $\mathrm{G} 2 / \mathrm{M}$ cell cycle, and induces apoptosis (Nicolini et al., 2014). In another study, the cytotoxicity of TMT toward HepG2 and PLC/PRF/5 liver cancer cells and nude mice tumor xenograft was reported (Xu et al., 2019). In liver cancer cells, TMT suppresses cell viability via apoptosis, lactate dehydrogenase (LDH) release, caspase-3 activation, ROS accumulation, and decreased mitochondrial membrane potential. In liver tumor xenograft, TMT enhances the expression levels of proapoptotic proteins, including Bax and cleaved caspase-3, and inhibits the expression levels of antiapoptotic proteins. Both in vitro and in vivo studies showed that TMT significantly suppressed the phosphorylation of ERK and AKT in liver cancer cells and tumors (Xu et al., 2019).

\section{Structure-activity relationship (SAR) studies}

There are very few structure-activity relationship (SAR) studies on DMT and TMT related to anticancer activities. In a study of the inhibitory effects of MDR proteins 1 (MRP 1), an important mechanism in MDR during cancer treatment, methylated flavonoids are among the best inhibitors with $\mathrm{IC}_{50}$ values ranging from 2.7 to $14.3 \mu \mathrm{M}$ (van Zanden et al., 2005). Inhibition at 25 
Table 2. Anticancer effects and molecular mechanisms of TMT.

\begin{tabular}{|c|c|}
\hline Cancer cell line and type & Anticancer effect and molecular mechanism of TMT (reference) \\
\hline K562/ADR leukemia & $\begin{array}{l}\text { Inhibits cell proliferation in a concentration- and time-dependent manner, induces apoptosis, and arrests G2/M cell cycle (Nicolini et al., } \\
\text { 2014) }\end{array}$ \\
\hline HepG2 and PLC/PRF/5 liver & $\begin{array}{l}\text { Suppresses cell viability via enhanced cell apoptosis, LDH release, caspase-3 activation, and ROS accumulation and decreases mitochondrial } \\
\text { membrane potential (Xu et al., 2019). Phosphorylation of ERK and AKT in liver cancer cells is significantly suppressed }\end{array}$ \\
\hline $\begin{array}{l}\text { Nude mice with HepG } 2 \text { and PLC/PRF/5 } \\
\text { liver xenograft tumor }\end{array}$ & $\begin{array}{l}\text { Enhances the expression levels of proapoptotic proteins (including Bax and cleaved caspase-3) and inhibits the expression levels of } \\
\text { antiapoptotic proteins after 14-day administration (Xu et al., 2019). Phosphorylation of ERK and AKT in xenograft liver tumors is } \\
\text { significantly suppressed }\end{array}$ \\
\hline
\end{tabular}

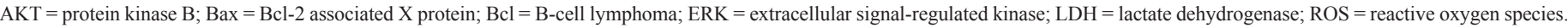

$\mu \mathrm{M}$ and $\mathrm{IC}_{50}$ values was $84 \%$ and $2.7 \mu \mathrm{M}$ for DMT and $68 \%$ and $7.4 \mu \mathrm{M}$ for TMT. DMT was the strongest, while TMT ranked third. Values of DMT and TMT were stronger than luteolin and quercetin, suggesting that the 4'-methyl ether moieties of DMT and TMT contribute to their inhibitory effects. In another study on the inhibitory effects of flavonoids on NF- $\mathrm{BB}$ signaling in MDAMB-231 breast cancer cells, DMT (3.7\%) displayed stronger inhibition than TMT (2.4\%) (Amrutha et al., 2014). Inhibitory values of DMT and TMT were stronger than luteolin (3.0\%) and much weaker than quercetin $(3.7 \%)$, respectively.

\section{CONCLUSION}

Flavonoids are the largest family of phenolic secondary metabolites from plants. They have a molecular structure consisting of two benzene rings (A and $\mathrm{B}$ ) joined by a pyran ring (C) forming a benzo-pyrone (C6-C3-C6) moiety. The majority of the flavonoids have the $\mathrm{B}$ ring linked in position 2 to the $\mathrm{C}$ ring, and they can be further divided into classes such as flavones, flavonols, flavanones, and flavanols. Studies have shown that the presence or absence of some functional moieties is associated with enhanced cytotoxicity toward cancer cells. They include $\mathrm{C} 2-\mathrm{C} 3$ double bond, a 4-carbonyl group, and a $\mathrm{C} 3$ hydroxyl group at ring $\mathrm{C}$ and the pattern of hydroxylation (ortho or meta) at ring B.

DMT and TMT are methylated flavonoids. DMT is a methoxyflavone having three hydroxyl groups, while TMT is a methoxyflavonol with four hydroxyl groups. This review on the anticancer properties of DMT and TMT supported the view that flavones without the $\mathrm{C} 3$ hydroxyl group are stronger in cytotoxicity against cancer cells than flavonols with the C3 hydroxyl group. However, further investigations are needed to confirm the role of the C3 hydroxyl group in cytotoxicity toward cancer cells.

Further clinical research on DMT and TMT is warranted to evaluate their safety and chemopreventive efficacy when used alone or in combination with other chemotherapy agents. Current knowledge of their pharmacokinetics, bioavailability, and SAR studies is meager. Further research on the structural modifications of DMT and TMT is needed for the synthesis of novel derivatives with enhanced inhibitory effects against different cancer cells and reduced cytotoxicity toward normal cells. For lesser-known bioactive compounds, such as DMT and TMT, their use in purified and standardized extracts containing chemical constituents that have the desired pharmacological activity may be the most practical approach. While Western medicine employs pure and single compounds, Chinese medicine (CM) has long used different combinations of compounds in the form of medicinal herbs to treat, ameliorate, and relieve the symptoms of different diseases. CM may have fewer and less severe side effects than single pure drugs, making them especially attractive to consumers. The development and clinical usage of different formulations of DMT and TMT with synergistic anticancer effects, reduced side effects, and acceptable quality control remain a major challenge. Little is known about the pharmacology and anticancer properties of DMT and TMT. The potentials for further research into these aspects of the two lesser-known methylated flavonoids are enormous. This will generate much research interest among medicinal chemists and researchers who are keen on lesser-known flavonoids.

\section{ACKNOWLEDGMENTS}

The authors are most grateful for the financial support provided by the UCSI University Research Excellence and Innovative Grant (REIG-FAS-2020/027).

\section{AUTHOR CONTRIBUTIONS}

All authors made substantial contributions to conception and design, acquisition of data, or analysis and interpretation of data; took part in drafting the article or revising it critically for important intellectual content; agreed to submit to the current journal; gave final approval of the version to be published; and agree to be accountable for all aspects of the work. All the authors are eligible to be an author as per the international committee of medical journal editors (ICMJE) requirements/guidelines.

\section{CONFLICTS OF INTEREST}

The authors report no financial or any other conflicts of interest in this work.

\section{PUBLISHER'S NOTE}

This journal remains neutral with regard to jurisdictional claims in published institutional affiliation.

\section{REFERENCES}

Abad-García B, Garmón-Lobato S, Sánchez-Ilárduya MB, Berrueta LA, Gallo B, Vicente F, Alonso-Salces RM. Polyphenolic contents in Citrus fruit juices: authenticity assessment. Eur Food Res Technol, 2014; 238:803-18.

Abotaleb M, Samuel SM, Varghese E, Varghese S, Kubatka P, Liskova A, Büsselberg D. Flavonoids in cancer and apoptosis. Cancers, $2019 ; 11(1): 28$

Amrutha K, Nanjan P, Shaji SK, Sunilkumar D, Subhalakshmi $\mathrm{K}$, Rajakrishna L, Banerji A. Discovery of lesser-known flavones as inhibitors of NF- $\mathrm{KB}$ signaling in MDA-MB-231 breast cancer cells-A SAR study. Bioorg Med Chem Lett, 2014; 24:4735-42.

Androutsopoulos VP, Mahale S, Arroo RR, Potter G. Anticancer effects of the flavonoid diosmetin on cell cycle progression and proliferation of MDA-MB 468 breast cancer cells due to CYP1 activation. Oncol Rep, 2009a; 21(6):1525-8. 
Androutsopoulos VP, Spandidos DA. The flavonoids diosmetin and luteolin exert synergistic cytostatic effects in human hepatoma HepG2 cells via CYP1A-catalyzed metabolism, activation of JNK and ERK and P53/P21 up-regulation. J Nutr Biochem, 2013; 24(2):496-504.

Androutsopoulos VP, Wilsher N, Arroo RR, Potter GA. Bioactivation of the phytoestrogen diosmetin by CYP1 cytochromes P450. Cancer Lett, 2009b; 274:54-60.

Bajraktari G, Weiss J. The aglycone diosmetin has the higher perpetrator drug-drug interaction potential compared to the parent flavone diosmin. J Funct Foods, 2020; 67:103842.

Ballard CR, Junior MR. Health benefits of flavonoids. In: Segura MR (ed.). Bioactive compounds. Cambridge, UK: Woodhead Publishing, pp 185-201, 2019.

Bhatt PR, Benzeroual KE. Neuroprotective effects of fisetin and diosmetin, alone and in combination, on lipopolysaccharide-induced neuronal cells. FASEB J, 2013; 27(1):1175-8.

Boumendjel A. Aurones: a subclass of flavones with promising biological potential. Curr Med Chem, 2003; 10:2621-30.

Caristi C, Bellocco E, Gargiulli C, Toscano G, Leuzzi U. Flavone-di-C-glycosides in citrus juices from southern Italy. Food Chem, 2006; 95(3):431-7.

Chahar MK, Sharma N, Dobhal MP, Joshi YC. Flavonoids: a versatile source of anticancer drugs. Pharmacogn Rev, 2011; 5(9):1-12.

Chang H, Mi M, Ling W, Zhu J, Zhang Q, Wei N, Zhou Y, Tang Y, Yuan J. Structurally related cytotoxic effects of flavonoids on human cancer cells in vitro. Arch Pharm Res, 2008; 31(9):1137-44.

Chen X, Wu Q, Chen Y, Zhang J, Li H, Yang Z, Yang Y, Deng Y, Zhang L, Liu B. Diosmetin induces apoptosis and enhances the chemotherapeutic efficacy of paclitaxel in non-small cell lung cancer cells via Nrf2 inhibition. J Chromatogr B Analyt Technol Biomed Life Sci, 2019b; 176:2079-94.

Chen X, Xu L, Guo S, Wang Z, Jiang L, Wang F, Zhang J, Liu B. Profiling and comparison of the metabolites of diosmetin and diosmin in rat urine, plasma and faeces using UHPLC-LTQ-Orbitrap MS ${ }^{\mathrm{n}}$. J Chromatogr B Analyt Technol Biomed Life Sci, 2019a; 1124:58-71.

Choi J, Lee DH, Park SY, Seol JW. Diosmetin inhibits tumour development and block tumour angiogenesis in skin cancer. Biomed Pharmacother, 2019; 117:109091.

Darsandhari S, Dhakal D, Shrestha B, Lee S, Jung N, Jung HJ, Sohng JK. Biosynthesis of bioactive tamarixetin in recombinant Escherichia coli. Biotechnol Appl Biochem, 2020; https:doi.org/10.1002/ bab.1958.

Delgado L, Fernandes I, González-Manzano S, de Freitas V, Mateus N, Santos-Buelga C. Anti-proliferative effects of quercetin and catechin metabolites. Food Funct, 2014; 5(4):797-803.

Fan C, Li Y, Yang H, Cui Y, Wang H, Zhou H, Zhang J, Du B, Zhai Q, Wu D, Chen X. Tamarixetin protects against cardiac hypertrophy via inhibiting NFAT and AKT pathway. J Mol Histol, 2019; 50(4):343-54.

Guven H, Arici A, Simsek O. Flavonoids in our foods: a short review. J Basic Clin Health Sci, 2019; 3:96-106.

Havsteen $\mathrm{BH}$. The biochemistry and medical significance of flavonoids. Pharmacol Ther, 2002; 96:167-202.

Hayamizu K, Morimoto S, Nonaka M, Hoka S, Sasaguri T. Cardiotonic actions of quercetin and its metabolite tamarixetin through a digitalis-like enhancement of $\mathrm{Ca}^{2+}$ transients. Arch Biochem Biophys, 2018; 637:40-7

Hostetler GL, Ralston RA, Schwartz SJ. Flavones: food sources, bioavailability, metabolism, and bioactivity. Adv Nutr, 2017; 8(3):423-35.

Hsu YL, Kuo PL. Diosmetin induces human osteoblastic differentiation through the protein kinase $\mathrm{C} / \mathrm{p} 38$ and extracellular signalregulated kinase 1/2 pathway. J Bone Miner Res, 2008; 23(6):949-60.

Kanadaswami C, Lee LT, Lee PP, Hwang JJ, Ke FC, Huang YT, Lee MT. The antitumor activities of flavonoids. In vivo, 2005; 19(5):95-909.

Kar Mahapatra D, Asati V, Bharti SK. An updated patent review of therapeutic applications of chalcone derivatives (2014-present). Expert Opin Ther Pat, 2019; 29(5):385-406.
Kar Mahapatra D, Bharti SK, Asati V. Anti-cancer chalcones: structural and molecular target perspectives. Eur J Med Chem, 2015; 98:69-114.

Kawaii S, Tomono Y, Katase E, Ogawa K, Yano M. Antiproliferative activity of flavonoids on several cancer cell lines. Biosci Biotechnol Biochem, 1999; 63(5):896-9.

Koosha S, Mohamed Z, Sinniah A, Alshawsh MA. Evaluation of anti-tumorigenic effects of diosmetin against human colon cancer xenografts in athymic nude mice. Molecules, 2019a; 24:2522.

Koosha S, Mohamed Z, Sinniah A, Alshawsh MA. Investigation into the molecular mechanisms underlying the anti-proliferative and antitumorigenesis activities of diosmetin against HCT-116 human colorectal cancer. Sci Rep, 2019b; 9(1):1-7.

Kopustinskiene DM, Jakstas V, Savickas A, Bernatoniene J. Flavonoids as anticancer agents. Nutrients, 2020; 12(2):457.Kuntz S, Wenzel U, Daniel H. Comparative analysis of the effects of flavonoids on proliferation, cytotoxicity, and apoptosis in human colon cancer cell lines. Eur J Nutr, 1999; 38(3):133-42.

Lesjak M, Beara I, Simin N, Pintać D, Majkić T, Bekvalac K, Orčić D, Mimica-Dukić N. Antioxidant and anti-inflammatory activities of quercetin and its derivatives. J Funct Foods, 2018; 40:68-75.

Li N, Liu JH, Zhang J, Yu BY. Comparative evaluation of cytotoxicity and antioxidative activity of 20 flavonoids. J Agric Food Chem, 2008; 56:3876-83.

Lin LZ, Harnly JM. Identification of the phenolic components of chrysanthemum flower (Chrysanthemum morifolium Ramat). Food Chem, $2010 ; 120: 319-26$

Liu B, Shi Y, Peng W, Zhang Q, Liu J, Chen N, Zhu R. Diosmetin induces apoptosis by up-regulating p 53 via the TGF- $\beta$ signal pathway in HepG2 hepatoma cells. Mol Med Rep, 2016a; 14(1):159-64.

Liu J, Ren H, Liu B, Zhang Q, Li M, Zhu R. Diosmetin inhibits cell proliferation and induces apoptosis by regulating autophagy via the mammalian target of rapamycin pathway in hepatocellular carcinoma HepG2 cells. Oncol Lett, 2016c; 12(6):4385-92.

Liu J, Wen X, Liu B, Zhang Q, Zhang J, Miao H, Zhu R. Diosmetin inhibits the metastasis of hepatocellular carcinoma cells by down-regulating the expression levels of MMP-2 and MMP-9. Mol Med Rep, 2016b; 13(3):2401-8.

Lopez-Lazaro M. Flavonoids as anticancer agents: structure-activity relationship study. Curr Med Chem Anticancer Agents, 2002; 2(6):691-714.

Lopez-Lazaro M, Galvez M, Martin-Cordero C, Ayuso MJ. Cytotoxicity of flavonoids on cancer cell lines. Structure-activity relationship. Stud Nat Prod Chem, 2002; 27:891-932.

Ma A, Zhang R. Diosmetin inhibits cell proliferation, induces cell apoptosis and cell cycle arrest in liver cancer. Cancer Manag Res, 2020; 12:3537-46.

Meng JC, Zhu QX, Tan RX. New antimicrobial mono-and sesquiterpenes from Soroseris hookeriana subsp. erysimoides. Planta Med, 2000; 66(6):541-4

Nicolini F, Burmistrova O, Marrero MT, Torres F, Hernández C, Quintana J, Estevez F. Induction of G2/M phase arrest and apoptosis by the flavonoid tamarixetin on human leukaemia cells. Mol Carcinog, 2014 53:939-50.

Oak C, Khalifa AO, Isali I, Bhaskaran N, Walker E, Shukla S. Diosmetin suppresses human prostate cancer cell proliferation through the induction of apoptosis and cell cycle arrest. Int J Oncol, 2018; 53(2):835-43.

Panche AN, Diwan AD, Chandra SR. Flavonoids: an overview. J Nutr Sci, 2016; 5:1-15.Park HJ, Lee SJ, Cho J, Gharbi A, Han HD, Kang TH, Kim Y, Lee Y, Park WS, Jung ID, Park YM. Tamarixetin exhibits antiinflammatory activity and prevents bacterial sepsis by increasing IL-10 production. J Nat Prod, 2018; 81(6):1435-43.

Patel K, Gadewar M, Tahilyani V, Patel DK. A review on pharmacological and analytical aspects of diosmetin: a concise report. Chin J Integr Med, 2013; 19:792-800. 
Plochmann K, Korte G, Koutsilieri E, Richling E, Riederer P, Rethwilm A, Schreier P, Scheller C. Structure-activity relationships of flavonoid-induced cytotoxicity on human leukaemia cells. Arch Biochem Biophys, 2007; 460:1-9.

Qiao J, Liu J, Jia K, Li N, Liu B, Zhang Q, Zhu R. Diosmetin triggers cell apoptosis by activation of the p53/Bcl-2 pathway and inactivation of the Notch3/NF-kB pathway in HepG2 cells. Oncol Lett, 2016; 12(6):5122-8.

Qiu M, Liu J, Su Y, Guo R, Zhao B, Liu J. Diosmetin induces apoptosis by down-regulating AKT phosphorylation via P53 activation in human renal carcinoma ACHN cells. Protein Peptide Lett, 2020; 27:1022-8.

Radušienė J, Ivanauskas L, Janulis V, Jakštas V. Composition and variability of phenolic compounds in Origanum vulgare from Lithuania. Biologija, 2008; 54(1):45-9.

Raffa D, Maggio B, Raimondi MV, Plescia F, Daidone G. Recent discoveries of anticancer flavonoids. Eur J Med Chem, 2017; 142:213-28.

Ren W, Qiao Z, Wang H, Zhu L, Zhang L. Flavonoids: promising anticancer agents. Med Res Rev, 2003; 23(4):519-34.

Roma A, Rota SG, Spagnuolo PA. Diosmetin induces apoptosis of acute myeloid leukaemia cells. Mol Pharmaceut, 2018; 15(3):1353-60.

Sak K. Cytotoxicity of dietary flavonoids on different human cancer types. Pharmacogn Rev, 2014; 8(16):122-46.

Sak K, Lust H, Kase M, Jaal J. Cytotoxic action of methylquercetins in human lung adenocarcinoma cells. Oncol Lett, 2018; 15(2):1973-8

Shao M, Wang Y, Jian YQ, Sun XG, Huang XJ, Zhang XQ, Ye WC. Chemical constituents of leaves of Psidium guajava. Chin J Chin Mater Med, 2014; 39(6):1024-9.

Singh M, Kaur M, Silakari O. Flavones: an important scaffold for medicinal chemistry. Eur J Med Chem, 2014; 84:206-39.

Sultanova N, Makhmoor T, Abilov ZA, Parween Z, Omurkamzinova VB, Choudhary MI. Antioxidant and antimicrobial activities of Tamarix ramosissima. J Ethnopharmacol, 2001; 78:201-5.

van Zanden JJ, Wortelboer HM, Bijlsma S, Punt A, Usta M, van Bladeren PJ, Rietjens IM, Cnubben NH. Quantitative structure activity relationship studies on the flavonoid mediated inhibition of multi-drug resistance proteins 1 and 2. Biochem Pharmacol, 2005; 69(4):699-708.

Wang C, Li S, Ren H, Sheng Y, Wang T, Li M, Zhou Q, He H, Liu C. Anti-proliferation and pro-apoptotic effects of diosmetin via modulating cell cycle arrest and mitochondria-mediated intrinsic apoptotic pathway in MDA-MB-231 cells. Med Sci Monit, 2019; 25:4639-47.

Wang HK. The therapeutic potential of flavonoids. Expert Opin Investig Drugs, 2000; 9(9):2103-19.
Wang TY, Li Q, Bi KS. Bioactive flavonoids in medicinal plants: Structure, activity and biological fate. Asian J Pharm Sci, 2018; 13(1):12-23.

Wang Y, Chen S, Yu O. Metabolic engineering of flavonoids in plants and micro-organisms. Appl Microbiol Biotechnol, 2011; 91(4):949-56

Xie YY, Yuan D, Yang JY, Wang LH, Wu CF. Cytotoxic activity of flavonoids from the flowers of Chrysanthemum morifolium on human colon cancer COLO 205 cells. J Asian Nat Prod Res, 2009; 11(9):771-8.

Xu J, Cai X, Teng S, Lu J, Zhou Y, Wang X, Meng Z. The pro-apoptotic activity of tamarixetin on liver cancer cells via regulation mitochondrial apoptotic pathway. Appl Biochem Biotechnol, 2019; 189:647-60.

Yadav DK, Bharitkar YP, Hazra A, Pal U, Verma S, Jana S, Singh UP, Maiti NC, Mondal NB, Swarnakar S. Tamarixetin 3-O- $\beta$-Dglucopyranoside from Azadirachta indica leaves: gastroprotective role through inhibition of matrix metalloproteinase-9 activity in mice. J Nat Prod, 2017; 80(5):1347-53.

Yang Y, Gong XB, Huang LG, Wang ZX, Wan RZ, Zhang P, Zhang QY, Chen Z, Zhang BS. Diosmetin exerts anti-oxidative, antiinflammatory and anti-apoptotic effects to protect against endotoxininduced acute hepatic failure in mice. Oncotarget, 2017; 8(19):30723.

Yoshikawa M, Uemura T, Shimoda H, Kishi A, Kawahara Y, Matsuda H. Medicinal foodstuffs. XVIII. Phytoestrogens from the aerial part of Petroselinum crispum Mill. (parsley) and structures of 6"-acetylapiin and a new monoterpene glycoside, petroside. Chem Pharm Bull, 2000; 48(7):1039-44.

Zhan G, Pan L, Tu K, Jiao S. Anti-tumour, antioxidant, and nitrite scavenging effects of Chinese water chestnut (Eleocharis dulcis) peel flavonoids. J Food Sci, 2016; 81:2578-86.

How to cite this article:

Chan EWC, Ng YK, Tan CY, Alessandro L, Wong SK, Chan HT. Diosmetin and tamarixetin (methylated flavonoids): a review on their chemistry, sources, pharmacology, and anticancer properties. J Appl Pharm Sci, 2021; 11(03):022-028. 